Proc $2^{\text {nd }}$ APCRS

\title{
Seasonal larval dispersal characteristics and sediment discharge impacts on the coral reefs in Lingayen Gulf, Philippines towards coastal ecosystem conservation
}

\author{
Kota ASHIKAWA ${ }^{1}$, Tanuspong POKAVANICH ${ }^{1, *}$, Aditya R. KARTADIKARIA ${ }^{1}$ \\ Kazuo NADAOKA', Cesar L. VILLANOY ${ }^{2}$ and Eugene C. HERRERA ${ }^{1}$ \\ ${ }^{1}$ Department of Mechanical and Environmental Informatics, Tokyo Institute of Technology, Japan \\ ${ }^{2}$ Marine Science Institute, University of the Philippines, The Philippines \\ * Corresponding author: Tanuspong POKAVANICH \\ E-mail: pokavanich.t.aa@m.titech.ac.jp
}

\begin{abstract}
Seasonal characteristics of larval dispersal originating from a reef and sediment discharge from a river are presented through results of hydrodynamic and particle tracking analysis simulations calibrated with field data at the Lingayen Gulf, Philippines. It is found that the seasonality was due to the prevailing monsoon system in the area as affected by local wind system and the spatial variation of mean sea level in the South China Sea. Results also suggested that only during the wet season (Southwest monsoon), there is a strong one-way connectivity between the reefs in the western to the eastern side of the gulf. Many coastal ecosystems on the western side of the gulf are more vulnerable to the environmental threats from excessive sediment and nutrient load discharged from Agno River during the dry season (North-East monsoon). Preliminary results from this study also revealed significant influences from offshore prevailing current to the gulf circulation which should not be neglected in the future studies in this area.
\end{abstract}

Keywords Coral reef, Larval dispersal, Sediment transport, Bolinao, Lingayen Gulf

\section{Introduction}

Lingayen Gulf is situated in the north-western part of Luzon Island in the Philippines (Figure 1). The gulf is around $35 \mathrm{~km}$ wide and $50 \mathrm{~km}$ long. It orients from northwest to south-east while its thalweg orients north to south. The gulf has wide mouth connecting to the South China Sea. The average depth at its mouth is around $200 \mathrm{~m}$ and around $20 \mathrm{~m}$ at the gulf-head. The system components of the gulf compose of coral reefs and seagrass beds along the shallow area on the western side and with Bolinao reef complex at the tip (Reef 1 in Figure 1). In contrast, there are not so many reefs along the eastern side. Reefs around San Fernando city, indicated as Reef 2 in Figure 1, appears to be one of the major reefs on the eastern side. The gulf is surrounded by high mountains in the western and eastern side and has relatively flat areas at around the head where Agno River mouth is situated. Meteorological setup including the wind system in this area is greatly influenced by North-East Monsoon (dry season) and South-West Monsoon (wet season). Intuitively, these characteristics might result in significant differences in water circulation, sediment transport as well as the connectivity between the reefs in the gulf. Related to these aspects, this paper presents results of numerical simula- 
tions calibrated with field observation to discuss the characteristic differences between dry and wet season.

\section{Material and methods}

\section{Field Observation}

The present study applied field observation data around Bolinao area obtained from two intensive field campaigns in dry season during North-East monsoon (15th-30th November, 2007) and wet season during South-West monsoon (11th-19th June, 2008). Details of the field observations program are given in Ashikawa et al. (2008) and their unpublished documents. Although not shown here, the water level and near-bottom flow velocity obtained from the automatic data logging sensors at Station BL1 (Figure 1) and Station BL2 were used to compare and calibrate the hydrodynamic simulations.

\section{Numerical Simulation}

The modeling work were carried out using the Delft3D modeling system that includes prior runs of hydrodynamic simulation using Delft3D-FLOW (WL Delft Hydraulics, 2007a) and particle tracking analyses using Delft3DPART (WL Delft Hydraulics, 2007b). Hydrodynamic model was forced by the water level variation, surface

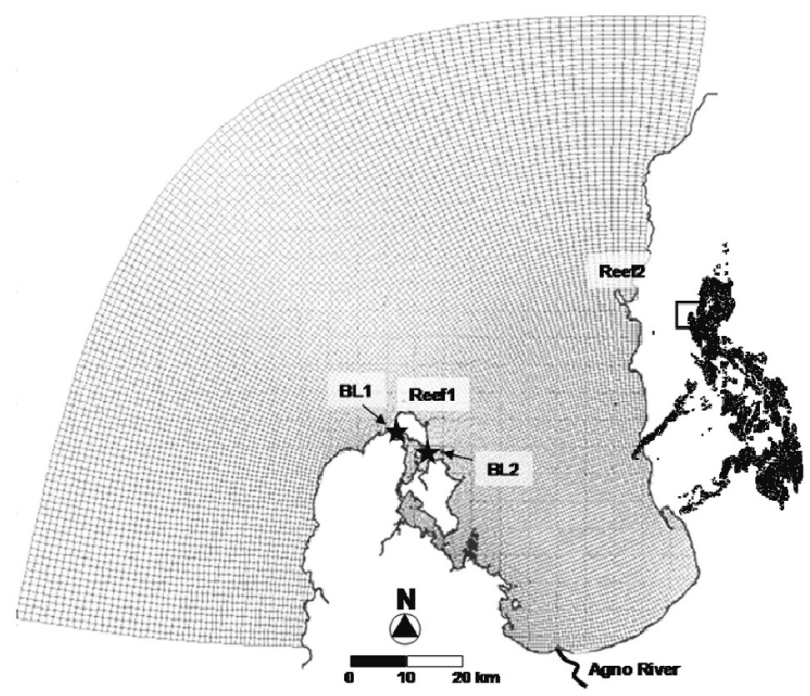

Fig. 1 Lingayen Gulf and its nested model mesh, locations of Reef 1, Reef 2, Station BL 1 and Station BL 2 and Agno River mouth wind stresses, Coriolis forces, bed shear stresses, turbulence-induced mass and momentum fluxes including subgrid scale turbulence. Delft3D-PART is a deterministic model, except for the processes related to the random displacement of the particle. It employs the Monte Carlo method for simulating the stochastic nature of particle movement by turbulence so the movements of particles in water are subjected to advection due to the currents, and to horizontal and vertical dispersion.

In the present study, the hydrodynamic model work composed of two hydrodynamic meshes i.e. the overall model and the nested model. The overall model applied the Spherical coordinate and the nested model applied the Cartesian coordinate. The horizontal orthogonal hydrodynamic meshes were designed to have the highest horizontal resolution around Bolinao area. The particle tracking simulation derived transport conditions from the database of the prior nested hydrodynamic runs. All simulation meshes have 4 vertical layers and were run at the same duration with the field observation in dry season in 2007 (5 m/s of North-East wind) and wet season in 2008 ( $5 \mathrm{~m} / \mathrm{s}$ of South-West wind). The simulations were run for one month having 2 weeks spin-up time. Although not shown here, the models provided reasonable reproducibility of the hydrodynamic condition when the simulated water level and flow velocity were compared with the observed ones.

\section{Results and discussions}

\section{Characteristic of Sea-level Fluctuation Offshore of the Lingayen Gulf}

Previous researches have pointed out the great variability in water level features in South China Sea. This phenomenon is a result from both short-term water level dynamics tidal influence (Pokavanich, 2009) and longterm mean sea level dynamic driven by seasonal meteorological forcing (Zhuang et al. 2010). The temporal and spatial water level variations specified at the offshore boundaries of the overall hydrodynamic model in the present study have already incorporated these two aspects. The prescribed water levels were derived from simulated mean sea levels from the regional hydrodynamic model 


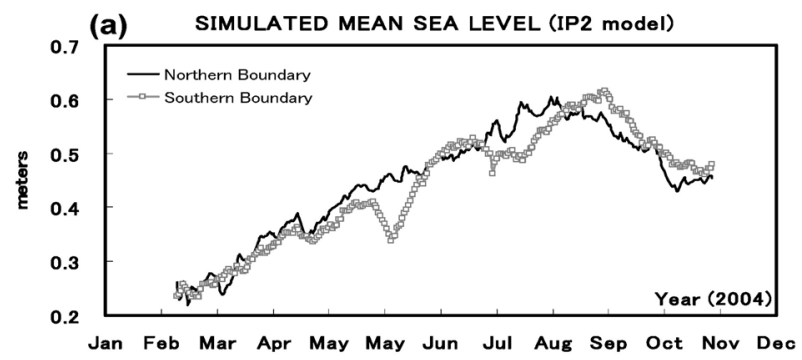

(b) Sea Level Fluctuation Obtained from IP2 model plus Nao99 model

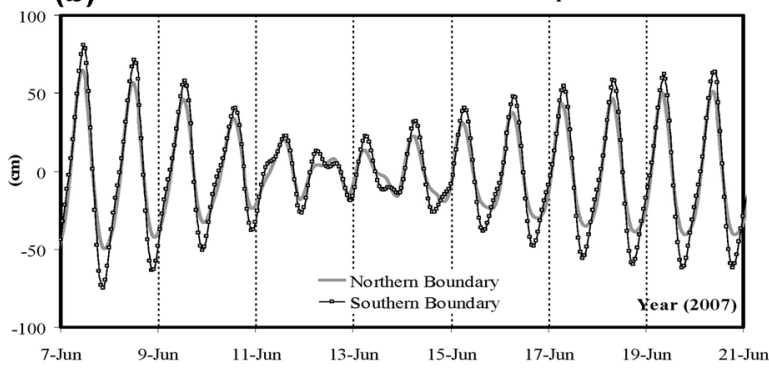

Fig. 2 Temporal variability of simulated (a) mean sea level and (b) tidal fluctuation derived from IP 2 model and Nao99.b model, respectively.

called "IP2 model" (Kartadikaria, personal com.) superimposed with the tidal prediction from Nao99.b model (Matsumoto et al. 2000). Examples of the data are shown in Figure 2. More importantly, it is seen from the Figure $2 \mathrm{a}$ that the mean sea level in the northern boundary is sometimes higher and sometimes lower compared to the one of the southern boundary. Figure $2 \mathrm{~b}$ suggested that the tidal fluctuation in the southern boundary is generally stronger compared to the one in the northern boundary. The combined effects of both features may result in alternating positive and negative sea level gradients that yield overall fluctuating mainstream current and the nonzero mean current directing northward and southward offshore of Lingayen Gulf.

\section{Hydrodynamic Feature of Lingayen Gulf}

It is found in the present study that the hydrodynamic condition offshore of Lingayen Gulf is governed by the sea level difference between the offshore northern and southern boundary. Although not shown here, the strongest offshore northward and southward currents occur during high and low tide, respectively. This characteristic sometime yields the semi-diurnal appearance of tidal current during diurnal variation of water level at Bolinao area. More importantly, hydrodynamic model resulting in from the 15 day-averaged flow velocity in field (Figure 3) suggests that the spatial variability is essential for the reproduction of realistic offshore prevailing currents. The mean current became negligible when the hydrodynamic simulation ignored the spatial variation of mean sea level, shown in Figure 3c. Note that the northward offshore prevailing current dominates in wet season and vice versa in dry season. Results of nested simulation are given in Figure 3d and Figure 3e during wet and dry seasons, respectively. It is seen that in addition to the significant hydrodynamic governing factor of tide, the results of nested simulation revealed that seasonal surface wind is another important factor, especially for the Lingayen Gulf circulation. The surface current in wet season, generally, moves to the north-east and defects to the north after reaching the west side of the Lingayen Gulf. Stronger current can be found along the shallow area in the gulf. In dry season, north-east wind forces the water mass to converge to the gulf-head and east side of the gulf. This yields diverging circulation in the gulf and results in apparently stronger currents along the west and east side of the gulf. Although not shown here, comparison between the hydrodynamic simulation with and without offshore strong current (ignore the spatial variability of mean sea level offshore) revealed some minor difference of water circulation inside the gulf however there were substantial differences when compared at the mouth and offshore of the gulf area.

\section{Characteristics of Larval Dispersal and Sediment Transport in Lingayen Gulf}

Four particle tracking analysis scenarios are presented in this paper. In the first and second scenarios, the particles were released from the Bolinao reef during North-East monsoon and South-West monsoon, respectively (Figure $4 \mathrm{a}$ and Figure $4 \mathrm{~b}$ ). The third and fourth scenarios have particles released from the Agno River mouth during North-East and South-West monsoon, respectively (Figure $4 \mathrm{c}$ and Figure $4 \mathrm{~d}$ ).

The snapshots of distribution of particle density after releasing time are given in Figure 4. Results reveal that there are significant differences between the particle distributions in each case. Particles released from the Bolinao reef (Reef1) seem to reach Reef 2 much quicker during 


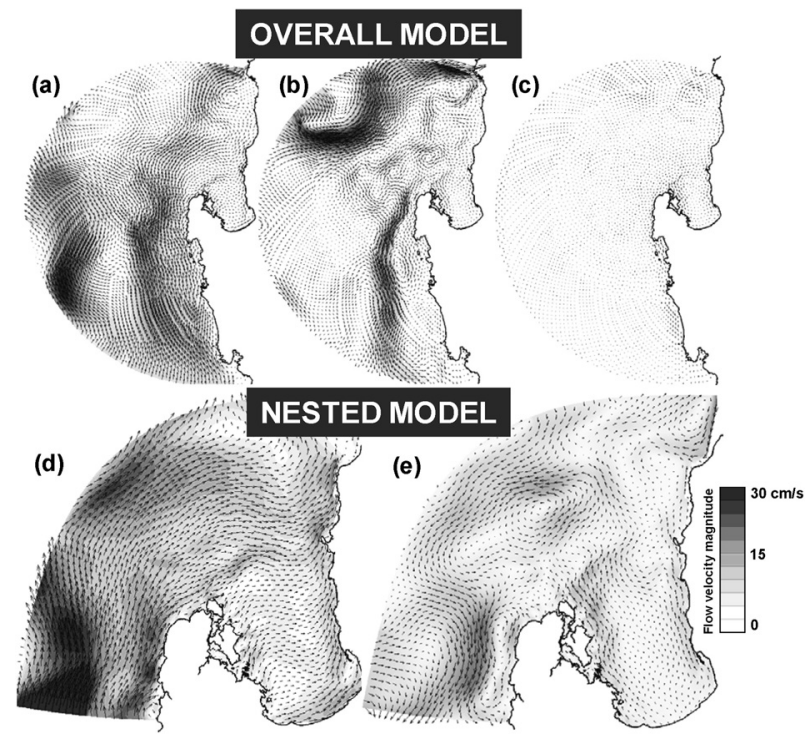

Fig. 3 Simulated 15 day-averaged surface flow velocity in field from the overall model and nested model in (a), (d) wet season (North-East Monsoon) and (b), (e) dry season (South-West Monsoon), and (c) when the effect of mean sea level was ignored.

the Southwest monsoon or wet season. However, they seem to have much longer residence time in the reef during Northeast monsoon or dry season. Also it is seen that there are significant difference between particle trajectories after being released from the Agno River mouth. The particles move along the west side of the gulf during dry season and pass the gulf-head and hug the east side of the gulf during wet season. Although not shown here, the distributions of particle according to the hydrodynamic data base that ignore the effect of offshore strong current show some significant difference with the one shown in this paper.

\section{Conclusions}

Based on the numerical modeling work calibrated with field data, the present study identified significant hydrodynamic and material transport differences between the Northeast monsoon (dry season) and Southwest monsoon (wet season) of Lingayen Gulf. There is a strong connectivity between the western and eastern side reefs system in the gulf during the wet season. On the other

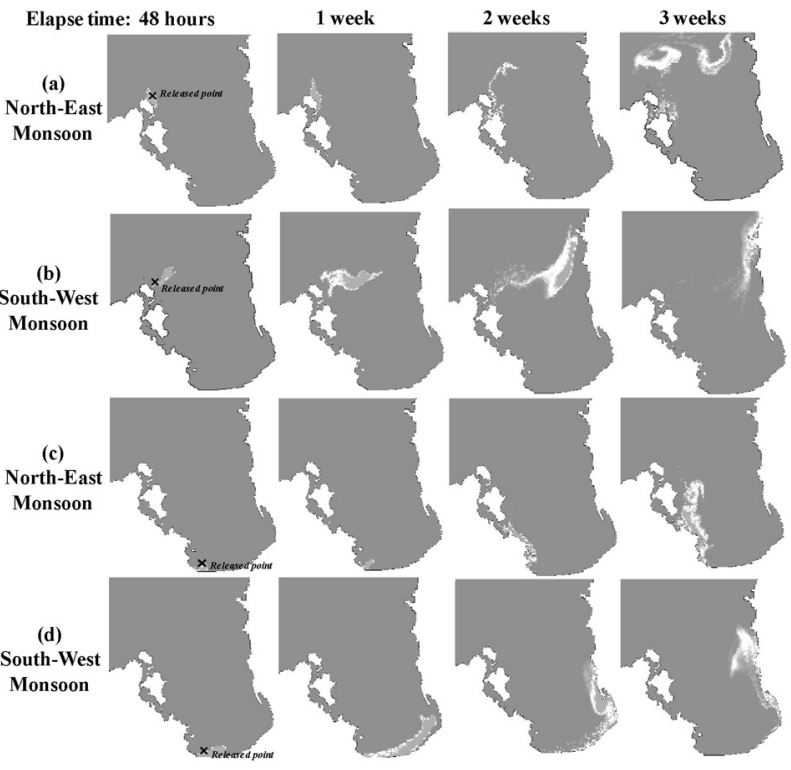

Fig. 4 Sequential presentation of passive particles from particle tracking analysis simulations after being released from Bolinao reef and Agno River mouth during (a), (c) dry season (Northeast Monsoon) and (b), (d) wet season (SouthWest Monsoon).

hand, there is weaker connectivity during dry season. More importantly, the sediment and nutrient plume discharged from Agno River are suggested to move differently between seasons. The plume moves toward the western side of the gulf and Bolinao area during Northeast monsoon. This implies that the many coastal ecosystems on the western side including the Bolinao reef are more vulnerable to threats from river discharges regardless of the tendency for new recruits from young larvae accumulated there due to higher residence time. In addition, the sediment and nutrient plume that moves toward the western side might also have detrimental effects to the young larvae supplied from the eastern side of the gulf. Implications of the findings of the present study suggest to promote the conservation and restoration of coral reefs and associated ecosystem in the west side of the gulf which is a potentially important source of the larvae to the eastern part. Reduction of sedimentation problem from Agno River to the western side reefs especially in dry season is recommended. Lastly, it should be noted that the preliminary hydrodynamic and material transport studies in this paper indicate the need for more detailed and sophisticated hydrodynamic simulation work that takes 
into account, not only transport resulting from tide and wind forcing but also density driven currents. This can add more realistic wind forcing to obtain a better understanding of the biophysical dynamics in Lingayen Gulf.

\section{Acknowledgements}

This research was supported by The Japan Society for the Promotion of Science (JSPS) Grant-in-Aid for Scientific Research (No.17206052, No. 18254003, No. 20246081, No. 20121007 and No.21254002), JSPS Core University Exchange Program, Asia-Pacific Network (APN) Grant (ARCP2006-08NMY-Nadaoka) and Japan Science and Technology Agency (JST) / Japan International Cooperation Agency (JICA) SATREPS Program.

\section{References}

Ashikawa K, Nadaoka K, Herrera EC, Yamamoto T, Villanoy CL, Salamante E (2008) Field observations and analyses of water quality characteristics in a dense aquaculture area adjacent to a coral reef in Bolinao, Philippines., JSCE 55
(2): $1426-1430$

Matsumoto K, Takanezawa T, Ooe M (2000) Ocean Tide Models Developed by Assimilating TOPEX/POSEIDON Altimeter Data into Hydrodynamical Model: A Global Model and a Regional Model Around Japan, J Oceanog 56: 567-581

Pokavanich T (2009): Field survey and numerical modeling analyses of physical and biogeochemical processes in semi-enclosed coastal waters, Doctoral thesis of Tokyo Ins of Tech, p 276

Pokavanich T, Nadaoka K, Blanco AC (2008) Comprehensive circulation and water quality investigation of the coastal lagoon: Puerto Galera, The Philippines. Proc 8th Int Conf on Hydro-science and Engineering, Nagoya, Japan, pp 406-415

WL Delft Hydraulics (2007a) Simulation of multi-dimensional hydrodynamic flows and transport phenomena, including sediments Delft 3D-FLOW release 3.14., p 642

WL Delft Hydraulics (2007b) Simulation of mid-field water quality and oil spill, using particle tracking, User Manual Delft 3D-PART. WL/ Delft Hydraulics, p 142

Zhuang W, Xie SP, Wang D, Taguchi B, Aiki H, Sasaki H (2010) Intraseasonal variability in sea surface height over the South China Sea. J Geophys Res 115 (c4): 0148-0227

C Japanese Coral Reef Society 